\title{
Comparison of surgical and conservative treatments for odontoid fractures in the elderly: results from three tertiary referral centers in the netherlands
}

\begin{abstract}
Objective: Odontoid fractures are the most common cervical spine fractures in elderly patients. The optimal treatment in this age group remains controversial. The goal of this study was to compare outcomes of surgical and conservative treatments.

Methods: A retrospective cohort study was conducted in three tertiary referral centers in the Netherlands. Patient records were reviewed for patients who met the selection criteria (i.e. age $\geq 55$ years, type II/III odontoid fractures). Fracture healing (union/stability) and clinical outcome (Likert scale) were assessed. The influence of age, applied treatment, and treatment strategy ('fracture based approach' or 'primarily conservative') was studied.

Results: A total of 105 patients was included (18 treated surgically, 87 treated conservatively; 52 treated with 'fracture based approach', 53 treated 'primarily conservative'). No difference was found in fracture union ( $68 \%$ overall) and fracture stability ( $88 \%$ overall). Data on clinical outcome were scarce, but did not differ between treatment groups. Patients $\geq 80$ years had worse outcomes in both applied treatment- and treatment strategy arms.

Conclusion: No radiological differences in outcome between surgical or conservative treatment (strategies) were observed. The majority of patients achieved fracture healing. The exact correlation between the quality of fracture healing (union or stability) and clinical outcome remains unclear. Advanced age ( $>80$ years) negatively influenced outcome.
\end{abstract}

Volume 7 Issue I - 2017

\author{
Jeroen GJ Huybregts, ${ }^{1,2}$ Wilco $\mathrm{CH}$ Jacobs, ${ }^{\prime}$ \\ Mark P Arts, ${ }^{2}$ Willem-Bart M Slooff, ${ }^{3} \mathrm{~F}$ \\ Cumhur Öner, ${ }^{4}$ Wilco C Peul, ${ }^{1,2}$ Carmen LA \\ Vleggeert-Lankamp' \\ 'Department of Neurosurgery, Leiden University Medical \\ Center, Netherlands \\ ${ }^{2}$ Department of Neurosurgery, Medical Center Haaglanden, \\ Netherlands \\ ${ }^{3}$ Department of Neurosurgery, University Medical Center \\ Utrecht, Netherlands \\ ${ }^{4}$ Department of Orthopaedics, University Medical Center \\ Utrecht, Netherlands
}

Correspondence: Jeroen GJ Huybregts, Department of Neurosurgery, Leiden University Medical Center, Albinusdreef 2, PO Box 9600, 2300 RC Leiden, Netherlands, Tel 3I (0) 7I 526 2।44, Email j.g.j.huybregts@lumc.nl

Received: October 28, 2016 | Published: January 06, 2017

Keywords: Odontoid fractures, Elderly, Surgical treatment, Conservative treatment, Cohort study

Abbreviations: LUMC, Leiden University Medical Center, Leiden, The Netherlands; $\mathrm{MCH}$, Medical Center Haaglanden, The Hague, The Netherlands; UMCU, University Medical Center Utrecht, Utrecht, The Netherlands; OR, Odds ratio; CI, Confidence interval; $\kappa$ = Kappa; P, P-value

\section{Introduction}

Accounting for $9-18 \%$ of cervical spine fractures in the elderly, odontoid fractures are the most common fractures of the geriatric cervical spine. As the population ages, the incidence is expected to increase. ${ }^{1-7}$

Treatment for odontoid fractures is either surgically or conservatively in nature. Surgical treatment involves anterior odontoid screw fixation or posterior (extended) atlanto-axial arthrodesis. Conservative treatment involves devices by which the patient's neck is immobilized, e.g. by halo-vest or hard cervical collar.

Particularly in the elderly, the choice for a particular treatment remains controversial. Elderly patients suffer from increased risks of surgical complications, as well as from increased risks of nonunion, deterioration of the cervical spine alignment and prolonged treatment duration when treated conservatively. Finding the right balance between fracture healing and treatment complications is often challenging. ${ }^{8-10}$

Recent literature reviews on this topic were inconclusive, due to limited quantity and quality of the available data. ${ }^{5,11,12}$ Recent clinical studies focused on survival and complications, but not on union, stability or clinical outcome. ${ }^{13,14}$ One study showed better outcomes for surgically treated type II fractures. ${ }^{15}$ Debate remains as to what the goal of treatment should be, as there is little evidence that fracture union and -stability clearly correlate to favorable clinical outcomes. ${ }^{12,16}$

The primary goal of this retrospective study was to compare outcomes of surgical and conservative treatment for odontoid fractures in the elderly. Radiological (union/stability) and clinical outcome were assessed. Particular focus was laid on the influence of age on treatment outcome ( $\geq 55-80$ versus $\geq 80$ years), and the correlation between radiological and clinical outcome. Potential prognostic factors were studied (i.e. fracture dislocation, baseline functioning).

\section{Materials and methods}

\section{Participating centers}

There are two regions in the Netherlands with similar populations but different treatment strategies for odontoid fractures. The Leiden University Medical Center (LUMC) and Medical Center Haaglanden $(\mathrm{MCH})$ are two hospitals following a fracture based approach. Surgical treatment is applied for dislocated fractures and relatively healthy patients. Conservative treatment is applied for non-dislocated fractures and patients in weak medical condition. The University Medical Center Utrecht (UMCU), on the other hand, follows a strategy of primarily conservative care always, irrespective of fracture characteristics and the patient's condition. These regions used these different strategies consistently during the last decades.

\section{Patient selection}

The data manager working for the LUMC and MCH conducted a sensitive search of the electronic patient records between 2000-2012. If necessary, hard-copy records were also consulted. The UMCU has 
two prospectively acquired databases available of patients treated for spinal injuries between 2001-2012. Using these databases, patients with odontoid fractures could easily be identified. All patients who met the selection criteria and were admitted in these years were included (Table 1).

Table I Selection criteria

Radiologically proven type II/III odontoid fracture according to the

Anderson and d'Alonzo classification ${ }^{19}$

$\geq 55$ years

$<2$ weeks after trauma

No previous treatment for odontoid fracture

No rheumatoid arthritis

No ankylosing spondylitis

Adequately documented treatment

Radiological follow-up data available

No medical ethics approval was necessary for this review. Patients admitted after 2012 were not included, as they were enrolled in a prospective study that is currently being conducted. ${ }^{17}$

\section{Data collection}

Data were gathered in a pre-developed Excel database. Two review authors $(\mathrm{JH} / \mathrm{CVL}$ for LUMC, JH/MA for MCH and JH/WBS for UMCU) scored patient characteristics, treatment data and outcome parameters (Table 2).

\section{Statistical analysis}

Statistical analyses were carried out using SPSS version 20. Summary statistics were calculated for demographic, treatment and outcome variables. T-tests were used for continuous variables. $\chi 2$ tests were used for categorical variables. ANOVA-analyses were used in cases of more than two groups. Analyses were two-sided. $\mathrm{P}$-values of $<0.05$ were considered significant differences. Intentionto-treat analyses were carried out. K-values were calculated to classify the inter-observer variability of the Anderson and d'Alonzo classification. $^{18}$

\section{Results}

\section{Patient selection}

The initial search identified 172 patients diagnosed with odontoid fractures. Of these, 67 patients were excluded as they did not meet the selection criteria. Main reasons for exclusions were age $<55$ and insufficient follow-up data. Hence, 105 patients were included (Figure 1). The demographic/baseline data (Table 3 ) and main results were assessed and compared (Table 4-Table 7).

Table 2 Data collection protocol

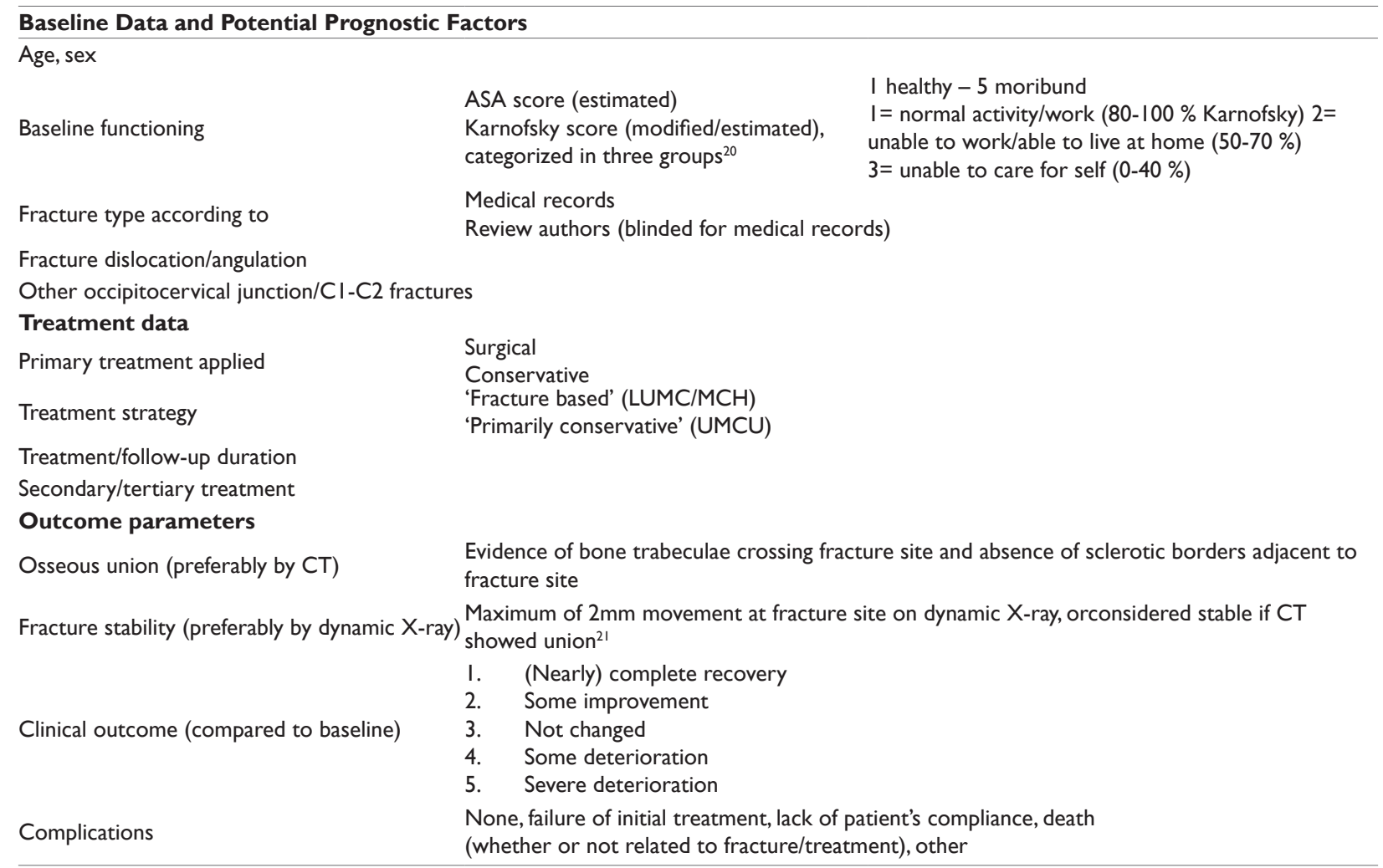

Table 3 Summary of demographic and baseline data of included patients

\begin{tabular}{lllll}
\hline & All $(\mathbf{n}=\mathbf{1 0 5})$ & Surgical $(\mathbf{n}=\mathbf{1 8})$ & Conservative $(\mathbf{n}=\mathbf{8 7})$ & P-value \\
\hline $\begin{array}{l}\text { Mean age (years) } \\
\text { Age groups (years) }\end{array}$ & 74.8 & 76.3 & 74.5 & 0.493 \\
Age $<80$ & 64 & $11(17 \%)$ & $53(83 \%)$ & 0.988 \\
Age $\geq 80$ & 41 & $7(17 \%)$ & $34(83 \%)$ & 0.794 \\
Sex & & & & $31(82 \%)$ \\
Male & 38 & $7(18 \%)$ & & \\
\hline
\end{tabular}


Table Continued...

\begin{tabular}{|c|c|c|c|c|}
\hline & All $(n=105)$ & Surgical $(n=\mid 8)$ & Conservative $(n=87)$ & P-value \\
\hline Female & 67 & II (I6\%) & $56(84 \%)$ & \\
\hline \multicolumn{5}{|l|}{ Baseline Functioning } \\
\hline $\begin{array}{l}\text { Average ASA score } \\
\text { (range I-5) }\end{array}$ & $2.6(n=45)$ & 2.7 & 2.6 & 0.286 \\
\hline Average Karnofsky score (range I-3) & $1.7(n=43)$ & 1.8 & 1.7 & 0.704 \\
\hline Fracture Type (medical records) & & & & 0.017 \\
\hline Type II & $55(52 \%)$ & $15(83 \%)$ & $40(46 \%)$ & \\
\hline Type III & $39(37 \%)$ & $3(17 \%)$ & $36(41 \%)$ & \\
\hline Unknown & 11 & 0 & 11 & \\
\hline Fracture Type (review authors) & & & & 0.156 \\
\hline Type II & $60(57 \%)$ & $13(72 \%)$ & $47(54 \%)$ & \\
\hline Type III & $45(43 \%)$ & $5(28 \%)$ & $40(46 \%)$ & \\
\hline Fracture Dislocation & & & & 0.63 \\
\hline No dislocation & $57(54 \%)$ & 8 & 49 & \\
\hline Dislocated/angulated anteriorly & $19(18 \%)$ & 5 & 14 & \\
\hline Dislocated/angulated laterally & $\mathrm{I}(\mathrm{I} \%)$ & 0 & I & \\
\hline Dislocated/angulated posteriorly & $28(27 \%)$ & 5 & 23 & \\
\hline Other $\mathrm{Cl} / \mathrm{C} 2$ fractures present & 18 (I7\%) & $4(22 \%)$ & $14(16 \%)$ & 0.53 \\
\hline
\end{tabular}

Table 4 Summary of the main results

\begin{tabular}{|c|c|c|}
\hline & Union & Stability \\
\hline Overall & 67 / $99(68 \%)$ & 86 / 98 (88\%) \\
\hline \multicolumn{3}{|l|}{ Applied Treatment } \\
\hline Surgical & $12 / 17(7 \mid \%)$ & 16 / 17 (94\%) \\
\hline Conservative & $55 / 82(67 \%)$ & $70 / 81$ (86\%) \\
\hline P-value & 0.778 & 0.379 \\
\hline \multicolumn{3}{|l|}{ Treatment Strategy } \\
\hline ‘Fracture based’ (LUMC/MCH) & 33 / $49(67 \%)$ & 44 / 49 (90\%) \\
\hline 'Primarily conservative' (UMCU) & $34 / 50(70 \%)$ & $42 / 49(86 \%)$ \\
\hline P-value & 0.945 & 0.538 \\
\hline \multicolumn{3}{|l|}{ Patient Age } \\
\hline Age $<80$ & $51 / 63(81 \%)$ & $61 / 62$ (98\%) \\
\hline Age $\geq 80$ & $16 / 36(44 \%)$ & $25 / 36(69 \%)$ \\
\hline P-value & 0 & 0 \\
\hline \multicolumn{3}{|l|}{ Patient Sex } \\
\hline Male & $26 / 36(72 \%)$ & $36 / 36(100 \%)$ \\
\hline Female & $4 I / 63(65 \%)$ & $50 / 62(81 \%)$ \\
\hline P-value & 0.465 & 0.005 \\
\hline \multicolumn{3}{|l|}{ Fracture Type } \\
\hline Type II & $32 / 56(57 \%)$ & $45 / 55$ (82\%) \\
\hline Type III & 35 / $43(81 \%)$ & $4 \mathrm{I} / 43(95 \%)$ \\
\hline P-value & 0.011 & 0.043 \\
\hline \multicolumn{3}{|l|}{ Fracture Dislocation/Angulation } \\
\hline Yes & $31 / 43(72 \%)$ & 40 / 43 (93\%) \\
\hline No & $36 / 56(64 \%)$ & $46 / 55$ (84\%) \\
\hline P-value & 0.41 & 0.16 \\
\hline \multicolumn{3}{|c|}{ Presence of other $\mathrm{Cl} / \mathrm{C} 2$ fractures } \\
\hline Yes & $13 / 17(77 \%)$ & $14 / 16$ (88\%) \\
\hline No & $54 / 82(66 \%)$ & 72 / 82 (88\%) \\
\hline P-value & 0.394 & 0.973 \\
\hline
\end{tabular}

Table 5 Clinical outcome, secondary treatment and treatment/follow-up duration

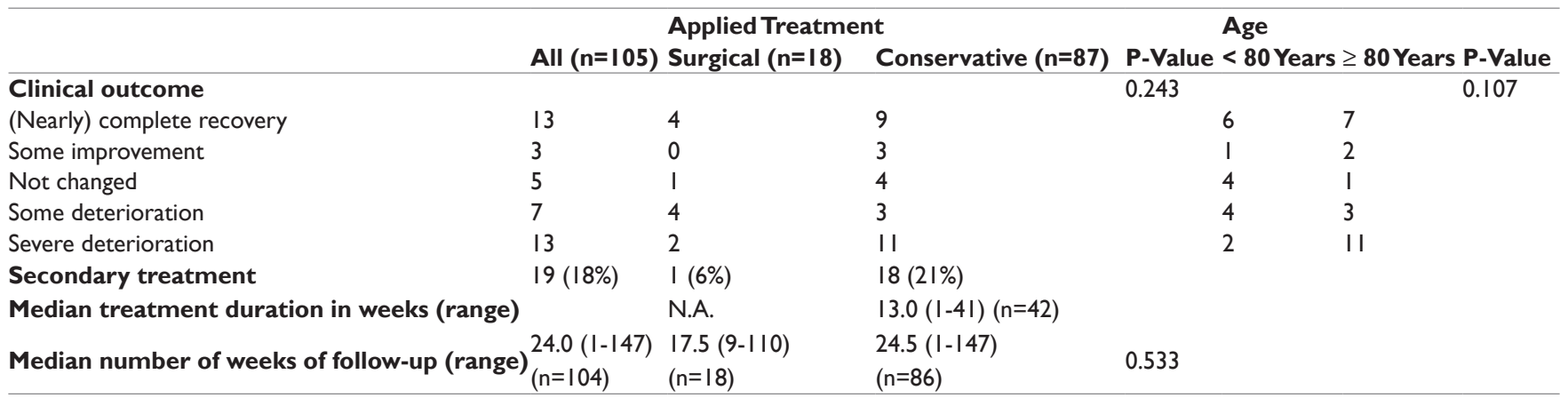


Table 6 Main results by age groups - (descriptive only because of small subgroups)

\begin{tabular}{|c|c|c|c|c|c|c|c|c|}
\hline & & \multicolumn{2}{|c|}{ Union } & \multicolumn{2}{|c|}{ Stability } & \multicolumn{3}{|c|}{ Complications } \\
\hline & & Yes & No & Yes & No & None & Failure initial treatment & Death \\
\hline \multirow{2}{*}{ Surgical treatment } & $<80$ years & 8 & 3 & II & 0 & II & 2 & \\
\hline & $\geq 80$ years & 4 & 2 & 5 & I & 5 & & 2 \\
\hline \multirow{2}{*}{$\begin{array}{l}\text { Conservative } \\
\text { treatment }\end{array}$} & $<80$ years & 43 & 9 & 50 & I & 50 & II & 2 \\
\hline & $\geq 80$ years & 12 & 18 & 20 & 10 & 24 & 6 & 9 \\
\hline \multirow{2}{*}{ Total } & $<80$ years & 51 & 12 & 61 & I & 61 & 13 & 2 \\
\hline & $\geq 80$ years & 16 & 20 & 25 & II & 29 & 6 & II \\
\hline
\end{tabular}

Table 7 Inter-observer variability of Anderson and d'Alonzo classification

\begin{tabular}{llll}
\hline Kappa $(\kappa)=.588$ & & Fracture Type According to Review Authors (Blinded Scoring) \\
\hline & & Type II & Type III \\
Fracture type according to medical records & Type II & 44 & II \\
& Type III & 8 & 3 I \\
\hline
\end{tabular}

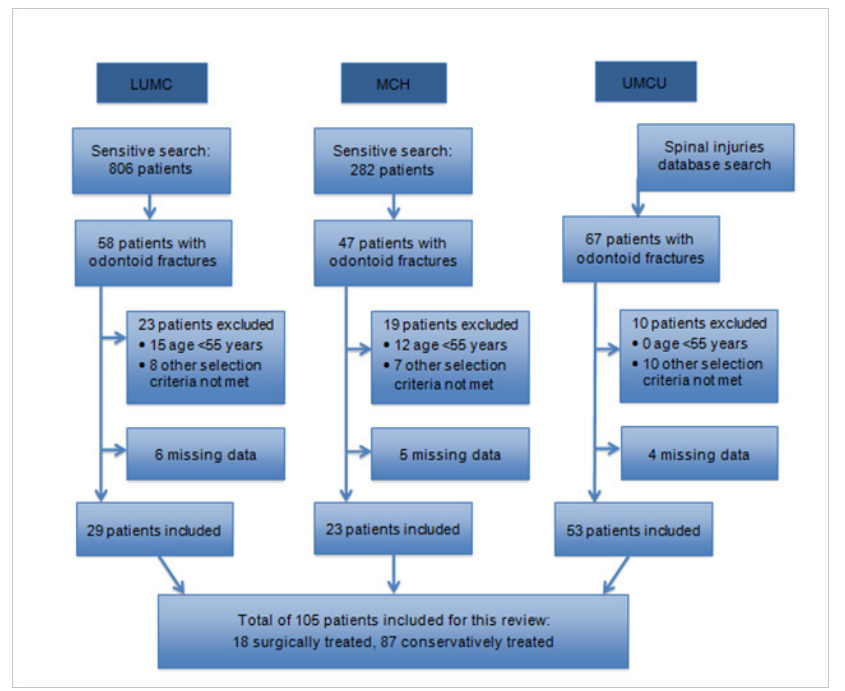

Figure I Flow chart of patient selection.

\section{Main outcome per treatment group}

Out of the 105 patients, 18 received primary surgical treatment (17 in LUMC/MCH, 1 in UMCU) and 87 primary conservative treatments. Surgical intervention consisted of anterior odontoid screw fixation in 5 patients and posterior (extended) atlanto-axial arthrodesis in 13 patients. In the conservative group, 62 patients received halovest treatment and 25 received a cervical collar. Median treatment duration for conservatively treated patients was 13.0 weeks (range $1-41, n=42)$. Overall median total follow-up period was 24 weeks (1147). Median follow-up was 17.5 weeks $(9-110)$ for surgically treated patients and 24.5 weeks (1-147) for conservatively treated patients $(\mathrm{p}=.533)$.

\section{Fracture union and stability}

No difference in outcome in terms of fracture union $(n=99$, $\mathrm{OR}=.849$; CI.271-2.655) and -stability $(\mathrm{n}=98$, OR=.398; CI.0483.307) was found between surgically and conservatively treated patients.

\section{Clinical outcome}

Clinical outcome could be established with certainty in only 41 patients. No difference in clinical outcome between surgically and conservatively treated patients was found based on these data $(p=.243)$. The influence of the quality of healing (union/stability) on clinical outcome could not be investigated due to insufficient data quantity.

\section{Prognostic factors \\ Demographic factors}

Patient $<80$ years were not treated differently than patients over $\geq 80$ years (OR=1.008; CI.356-2.855). The outcomes in terms of union $(\mathrm{OR}=.188$; CI.076-.468) and stability $(\mathrm{OR}=.037$; CI.005-.304) of patients $<80$ were better than in patients $\geq 80$ years. Median total follow-up duration was 24.5 weeks for patients $<80$ and 16.5 weeks for patients $\geq 80$ years. No difference in clinical outcome between these age groups was found $(\mathrm{p}=107)$, possibly because of the relatively small groups.

No influence of patient sex on the applied treatment was found $(\mathrm{OR}=1.150$; CI.405-3.266). Patient sex did also not influence the achievement of union (OR=.717; CI.293-1.753). Stability was, however, found significantly more in males compared to females $(\mathrm{OR}=1.240$; CI 1.098-1.401, 7 missing).

\section{Baseline functioning}

The average ASA and Karnofsky scores were equal in surgically and conservatively treated patients.

The average ASA scores at baseline of patients who achieved union and/or stability were not different from those who did not (ANOVAanalysis: $p=.267$ for union, $p=.281$ for stability). The average Karnofsky score at baseline of patients who achieved union was not different from patients who did not (ANOVA-analysis: $\mathrm{p}=.051$ ), but showed a better condition of patients who achieved stability $(\mathrm{n}=34)$ than those who did not ( $\mathrm{n}=6$; ANOVA-analysis: $\mathrm{p}=.008$ ).

\section{Fracture characteristics}

The review author's fracture scoring identified 60 type II and 45 type III fractures. Out of 60 patients with type II fractures, 13 underwent surgical and 47 conservative treatments; out of 45 patients with type III fractures, 5 underwent surgical and 40 conservative treatments $(\mathrm{OR}=2.213$; CI.726-6.743).

The inter-observer variability between the fracture scores of the authors and the initial patient records was $\kappa=.588$, indicating moderate reliability of the Anderson and d'Alonzo classification (Table 7). ${ }^{18}$

Fracture dislocation or angulation was present in $48(46 \%)$ patients (10 surgically, 38 conservatively treated). No influence of the presence of fracture dislocation/angulation was found on the achievement of 
union $(\mathrm{OR}=1.435$; CI .606-3.398) and stability $(\mathrm{OR}=2.609$; CI .66010.303).

No influence of the presence of other $\mathrm{C} 1 / \mathrm{C} 2$ fractures was found on the achievement of union (OR=1.685; CI.502-5.651) and stability $(\mathrm{OR}=.972$; CI.192-4.925). When corrected for the applied treatment, still no difference between patients with and without other $\mathrm{C} 1 / \mathrm{C} 2$ fractures was found on union $(\mathrm{p}=.140)$ and stability $(\mathrm{p}=.567)$.

\section{Treatment strategy (LUMC/MCH vs UMCU)}

Patients were treated with 'fracture based approach' (LUMC/ $\mathrm{MCH})$ in 52 cases, of which $17(33 \%)$ were in fact primarily treated surgically. In 7 cases, primary surgery was performed because it seemed most suitable given the fracture characteristics (e.g. dislocation). One patient received surgery at his own request. In 9 of the 35 patients primarily treated conservatively, this was based on specific fracture characteristics (e.g. non-displaced). Motivations were unclear in 35 of the 52 cases. 13 (25\%) patients received surgery as secondary treatment.

Patients were treated with 'primarily conservative' approach (UMCU) in 53 cases, of which 52 (98\%) were in fact primarily treated conservatively. In 42 cases, the surgeon's preference was decisive. One patient underwent surgery because he would not endure external immobilization. Motivations were unclear in 10 cases. 4 patients (8\%) underwent secondary surgery and 2 patients $(4 \%)$ received halo-vests as secondary treatment.

Outcomes between these strategies did not differ for union $(\mathrm{OR}=1.030$; CI.444-2.392) and stability $(\mathrm{OR}=.682$; CI.201-2.316) No conclusions could be drawn on difference in clinical outcome due to the relatively small patient numbers.

\section{Secondary/tertiary treatments}

Secondary treatment was necessary in 20 patients, of which 18 patients were primarily treated conservatively (12 with halo-vest, 6 with cervical collar). The average moment for secondary treatment was 16.2 weeks after starting the initial treatment (range 1-48).

One patient who was primarily treated with odontoid screw fixation had to undergo secondary posterior fixation. Another patient who was primarily treated with posterior fixation had to undergo secondary odontoid screw fixation, after which he achieved fracture stability but no union.

18 conservatively treated patients had to undergo secondary treatment, consisting of surgery in 16 cases and halo-vests in 2 cases. After secondary treatments, 12 of 16 patients achieved union (75\%, 2 missing) and 15 of 16 patients achieved stability (94\%, 2 missing).

Three patients required tertiary interventions by way of surgery at 18,30 and 34 weeks respectively, after they had already undergone surgery as secondary treatment.

\section{Complications and mortality}

In the surgically treated group, 2 of $18(11 \%)$ patients died (at 9 and 10 weeks, respectively, both $>80$ years). Secondary treatment was necessary in two patients, of whom one died. No major complications were recorded in the remaining 15 patients.

In the conservatively treated group, 11 of $87(13 \%)$ patients died (range 1-125 weeks, $8>80$ years). Secondary treatment was necessary in 18 patients. No major complications were recorded in the remaining 58 patients.
For the thirteen patients who died, the median moment of death was 10.5 weeks after admittance.

\section{Discussion}

The presented cohort of elderly patients with odontoid fractures is one of the largest in the available literature and thereby adds to the knowledge on the topic12. No difference in union and stability between different treatments was observed. Since this is a retrospective study, findings are probably subjected to concessions to the optimal treatment strategy as judged by the treating physician (e.g. surgery for severest cases in LUMC/MCH). Data on clinical outcome are scarce, but do not demonstrate a difference between the groups. No definitive recommendations for the choice between surgery and conservative treatment strategy can thus be made.

Patients between 55-80 years achieved significantly more union and stability compared to patients $>80$ years, regardless of the applied treatment. This supports the common hypothesis of deterioration of treatment outcome with advancing age. ${ }^{3}$

Patients with type III fractures showed both more fracture union and -stability compared to patients with type II fractures. These difference most likely results from larger bony contact areas and more adequate vascular supply of type III fractures, resulting in better fracture healing. ${ }^{3}$ There is, however, no strong evidence that different fracture types should be treated differently. Moreover, the Anderson and d'Alonzo classification was found to suffer from evident interobserver variability.

Contrary to the common presumption, the presence of odontoid fracture dislocation/angulation or multiple $\mathrm{C} 1 / \mathrm{C} 2$ fractures did not negatively influence treatment outcomes. A possible explanation is that the presence of dislocation/angulation or multiple fractures made treatments last longer and thereby showing the same results as patient with non-displaced/single fractures. Moreover, the presence of dislocation or multiple fractures is a common reason for primary surgery in the 'fracture based approach' of the LUMC/MCH, which may have caused heterogeneity in favor of the conservatively treated group. Male patients achieved slightly more fracture stability than female patients, for which no explanation or confounders were found. No difference in union was found between the sexes.

At baseline, average Karnofsky scores showed a better condition (i.e. healthier) of patients who achieved stability than those who did not. Karnofsky scores were comparable between patients who achieved union and those who did not. Likewise, baseline ASA scores were not predictive for the achievement of union and stability. Hence, no strong evidence was found to support claims of better outcomes for healthier patients.

The treatment duration and total follow-up period did not differ between treatments and treatment strategies ('fracture based' versus 'primarily conservative' strategies). The most common complications were failure of the initial treatment. 11 conservatively treated patients died, of which 8 were over 80 years of age. Although these numbers are too small to allow further analysis, there seems to be a higher mortality risk in patients over 80 years.

\section{Strengths and limitations}

The presented patient cohort is one of the largest available so far and thereby adds to the knowledge on the topic. The number of particularly the patients who were primarily treated surgically was, however, relatively small. This limited the analyses that could be performed. The retrospective nature of this study limits the reliability 
of the data that were found (e.g. missing data and interpretation of data by non-direct observers).

\section{Conclusion}

No difference in the achievement of fracture union, -stability or clinical outcome between surgically and conservatively treated patients was found. This may, however, be explained by group heterogeneity due to different selection mechanisms. Advanced age ( $\geq 80$ years) had a negative influence on treatment outcome in all treatment groups. Type III fractures showed better healing compared to type II fracture. No strong evidence was found for better outcomes in patients who are healthier at baseline or for worse outcomes in case of multiple/dislocated fractures.

\section{Implications for research}

Prospective studies with appropriate sample size may find prognostic factors for the success of either one of the treatments and evidence on the relation between fracture healing and clinical outcome. ${ }^{17}$ This would also provide a better understanding of the goal of treatment: to achieve fracture union, -stability, a favorable clinical outcome, or a combination of these.

\section{Acknowledgements}

The authors are thankful to data manager Mrs Maloe van Groeningen (LUMC/MCH), as well as to Mr Ruud Hiensch and his colleagues (UMCU) for their assistance in patient identification.

\section{Conflicts of interest}

None.

\section{References}

1. Butler JS, Dolan RT, Burbridge M, et al. The long-term functional outcome of type II odontoid fractures managed non-operatively. Eur Spine J. 2010;19(10):1635-1642.

2. Grauer JN, Shafi B, Hilibrand AS, et al. Proposal of a modified, treatment-oriented classification of odontoid fractures. Spine Journal. 2005;5(2):123-129.

3. Hsu WK, Anderson PA. Odontoid fractures: update on management. $J$ Am Acad Orthop Surg. 2010;18(7):383-394.

4. Koech F, Ackland HM, Varma DK, et al. Nonoperative management of type II odontoid fractures in the elderly. Spine (Phila Pa 1976). 2008;33(26):2881-2886.

5. Shears E, Armitstead CP. Surgical versus conservative management for odontoid fractures. Cochrane Database Syst Rev. 2008;(4):CD005078.

6. Harrop JS, Hart R, Anderson PA. Optimal treatment for odontoid fractures in the elderly. Spine (Phila Pa 1976). 2010;35(21 Suppl):S219S227.
7. White AP, Hashimoto R, Norvell DC, et al. Morbidity and mortality related to odontoid fracture surgery in the elderly population. Spine (Phila Pa 1976). 2010;35(9 Suppl):S146-S157.

8. Andersson S, Rodrigues $\mathrm{M}$, Olerud $\mathrm{C}$. Odontoid fractures: high complication rate associated with anterior screw fixation in the elderly. Eur Spine J. 20009(1):56-59.

9. Majercik S, Tashjian RZ, Biffl WL, et al. Halo vest immobilization in the elderly: a death sentence? J Trauma. 2005;59(2):350-356.

10. Reinhold M, Bellabarba C, Bransford R, et al. Radiographic analysis of type II odontoid fractures in a geriatric patient population: description and pathomechanism of the "Geier"-deformity. Eur Spine J. 201120(11):1928-39.

11. Pal D, Sell P, Grevitt M. Type II odontoid fractures in the elderly: an evidence-based narrative review of management. Eur Spine $J$. 201120(2):195-204.

12. Huybregts JG, Jacobs WC, Vleggeert-Lankamp CL. The optimal treatment of type II and III odontoid fractures in the elderly: a systematic review. Eur Spine J. 201322(1):1-13.

13. Fehlings MG, Arun R, Vaccaro AR, et al. Predictors of Treatment Outcomes in Geriatric Patients With Odontoid Fractures: AOSpine North America Multi-Centre Prospective GOF Study. Spine (Phila Pa 1976). 2013;38(11):881-886.

14. Chapman J1, Smith JS, Kopjar B, et al. The AOSpine North America Geriatric Odontoid Fracture Mortality Study: A Retrospective Review of Mortality Outcomes for Operative versus Non-Operative Treatment in 322 Patients with Long-Term Follow-Up. Spine (Phila Pa 1976). 2013;38(13):1098-1104.

15. Vaccaro AR1, Kepler CK, Kopjar B, et al. Functional and quality-oflife outcomes in geriatric patients with type-II dens fracture. $J$ Bone Joint Surg Am. 2013;95(8):729-735.

16. Smith JS1, Kepler CK, Kopjar B, et al. Effect of type II odontoid fracture nonunion on outcome among elderly patients treated without surgery: based on the AOSpine North America geriatric odontoid fracture study. Spine (Phila Pa 1976). 201338(26):2240-2246.

17. Huybregts JG, Jacobs WC, Peul WC, et al. Rationale and design of the INNOVATE Trial: an international cooperative study on surgical versus conservative treatment for odontoid fractures in the elderly. $B M C$ Musculoskelet Disord. 2014;15(1):7.

18. Viera AJ, Garrett JM. Understanding interobserver agreement: the kappa statistic. Fam Med. 2005;37(5):360-363.

19. Anderson LD, D'Alonzo RT. Fractures of the odontoid process of the axis. J Bone Joint Surg Am. 1974;56(8):1663-1674.

20. Hospice Patients Alliance: Karnofsky Perfomance Status Scale Definitions Rating (\%) Criteria.

21. Knopp R, Parker J, Tashjian J, et al. Defining radiographic criteria for flexion-extension studies of the cervical spine. Ann Emerg Med. 2001;38(1):31-35. 